\title{
La especificidad organizativa del tercer sector: tipos y dinámicas
}

\author{
M anuel Herrera Gómez \\ Universidad de G ranada. D epartamento de Sociología \\ 18014 Granada. Spain
}

\section{Resumen}

En las últimas décadas ha crecido el interés por aquellos sujetos asociativos, con grado diverso de formalización e institucionalización, que se sitúan en el espacio público entre el Estado y el mercado. M uy numerosas y diferentes son las denominaciones utilizadas: organizaciones sin fines de lucro, tercer sector, privado social, tercer sistema, etc. Estas páginas intentan aportar una contribución desde una óptica sociológica y de teoría de las organizaciones. Tras anal izar críticamente las aportaciones más significativas de los estudiosos de management, se intentan individuar las características específicas de un nuevo tipo de organizaciones que se diferencian tanto de las ubicadas en el sector público, como de las situadas en el sector privado.

Palabras clave: sociología de las organizaciones, tercer sector, organizaciones sin fines de lucro.

Abstract. The specifity of third sector: types and dinamics

The interest for the associative subjetcs situated among State and market has grown in the last decades. $M$ any different names has been used for this associative subjects with a diverse range or formalitation and institutionalitation: non profit organizations, third sector, social private, third system, etc. These pages try to supply a contribution from the sight of a sociology of the organizations theory. It tells about the main and more meaningful aportations of the management experts. This is the start point to individualize the specific characters of a king of organizations that are quite different from those of the public sector and the market.

Key words: organizations sociology, third sector, non profit organizations.

\section{Sumario}

1. Premisas

2. Variedad y diferencia en las organizaciones del tercer sector

3. Tipos de organizaciones del tercer sector
4. Factores y procesos de cambio

5. Características específicas de las organizaciones del tercer sector

6. Conclusiones

Bibliografía 


\section{Premisas}

Para buena parte de la opinión española, las organizaciones del tercer sector o non profit se identifican con el voluntariado. Es decir, con una imagen bastante ideal izada de personas que se comprometen gratuitamente para asistir a pobres, ancianos, minusválidos, enfermos, etc.; para proteger el ambiente; para socorrer a poblaciones que han sufrido desastres naturales; para organizar actividades deportivas o para promover iniciativas culturales.

Ante todo, aclarar que las organizaciones del tercer sector no son necesariamente de voluntariado, en el doble sentido de que no sólo se basan en el trabajo de los voluntarios y en las donaciones voluntarias; que no son ni siquie ra nonprofit, si con este término se entiende que no pueden obtener beneficios por sus actividades; que no intervienen sólo en aquellos sectores o en aquellas actividades que de por sí excluyen el interés de empresas económicas, en cuanto sectores 0 actividades no beneficiosas económicamente. Q uien enfatiza la natural eza desinteresada, de puro don y de total gratuidad de las organizaciones del tercer sector, también debe tener en cuenta que:

a) las organizaciones del tercer sector constituyen un campo de actividades que a menudo sirve para entrar en el mundo profesional;

b) estas organizaciones tienen necesidad de una cierta cal culabilidad económica (por tanto, usan el dinero y otros medios de mercado);

c) tienen la obligación de adecuarse a normas legales (condiciones puestas por el Estado).

En breve, las organizaciones del tercer sector no pueden ser identificadas tout court con islas de marginalidad como pueden ser las acciones de compasión, de beneficencia, de asistencia al necesitado. M ás bien, la cultura de estas organizaciones aspira a combinar ciertas motivaciones ideales con formas de intervención eficaces, dotadas de estabilidad, respondiendo por su relacionalidad a necesidades social es no ocasionales, sino profundamente afincadas en el tejido social. En mi opinión, la cultura propia de las organizaciones del tercer sector puede ser leída e interpretada como exigencia de encontrar nuevas formas de mix entre Gemeinschaft y Gesel schaft. Aquí encontramos el carácter relacional (reticular) de las identidades y de los intereses de los nuevos «sujetos social es» que estoy analizando. Se trata de identidades que se forman en estrecha interacción con intereses que no pueden ser definidos sólo o principalmente en sentido instrumental, y que, por otra parte, no pueden ser considerados «a priori» como gratuitos o de puro y simple altruismo. La cultura de las organizaciones del tercer sector espacia en su interior todas las relaciones que están entre el beneficio y el no beneficio, entre la intersubjetividad de los ciudadanos y las acciones del Estado1.

1. Véanse A. Melucci (1984); L. Boccacin (1993); M. Archer (1995); I. Colozzi, A. BASSI (1995); P. D ONATI (1996). 
Por tanto, decir qué no son las organizaciones del tercer sector es relativamente fácil. La misma definición del tercer sector, en el fondo, posee unos rasgos más negativos que positivos: «dice que es un sector constituido por organizaciones que no son públicas y no son de mercado, sino que lo identifica como sector residual que contiene aquellas organizaciones que no se engloban ni en el Estado, ni en el mercado»?. Para dar una dignidad analítica a esta categoría residual es necesario saber decir en positivo qué caracteriza y, simultáneamente, diferencia las organizaciones que definimos de Tercer Sector, respecto a aquellas que asignamos al Estado y al M ercado.

En estas páginas trataré, ante todo, de aclarar que crear una organización del tercer sector es una «elección general izable», es decir, «un recorrido de acción» que no se vincula a particulares ámbitos o sectores de actividad, sino tendencialmente a todos${ }^{3}$. Su generalidad implica que este modo de obrar se especifica según modalidades diferenciadas y relacionalmente adecuadas al tipo de ambiente/objetivo al que la singular organización se refiere. Para ilustrar las

2. El hecho de subrayar el carácter «tercero» del fenómeno que estamos analizando, por una parte, configura el propio referente empírico por negación, pero, por otra, lo ubica en estre cha relación con los otros dos sectores de la sociedad: Estado y mercado. La pérdida, en términos de identidad, derivada del hecho de ser caracterizado a partir de lo que no es, más que teniendo como referente las características positivas, viene compensada con las ventajas que el término ofrece. Pienso que favorece el desarrollo de un proceso de sensibilización social y de información que podría conducir, en un periodo razonable de tiempo, a la equiparación entre los tres sectores a nivel societario (en términos de visibilidad, de reconocimiento de las propias aportaciones al bienestar de la población, de recursos activados, de respuestas elaboradas a determinadas necesidades sociales, etc.). Por tanto, el término expresa más un «deber ser» que la referencia a un estado de hecho actual.

3. En consecuencia, emerge un interrogante: ¿Qué procesos dan vida al tercer sector y sus organizaciones? U na posible respuesta es la siguiente: en cuanto que la organización del tercer sector es un sujeto social, compuesto de un conjunto de personas que comparten y participan de una relación que es sentida, vista y actuada como referente simbólico-intencional y como ligamente estructural, son las mismas redes sociales que, después de haberse diferenciado, deben producir esferas de relaciones cuya «especialización» estructural, cultural y organizativa consiste en integrar (o al menos relacionar de manera solidaria) aque Ilo que ha sido diferenciado. Los procesos que originan el tercer sector son, por tanto, procesos de diferenciación reticular, en cuanto que representan la creación de redes más complejas que las que daban «orden» a la sociedad procedente: por una parte, las redes del tercer sector son más fluidas, móviles y contingentes; por otra, son capaces de dotarse de nuevas formas de relacionamiento que son las organizaciones del tercer sector.

El tercer sector y sus organizaciones viven de la reticularidad de la sociedad, es decir, de ser esta última relación variable entre sujetos. Como el cuerpo humano tiene necesidad de aire para respirar, también la persona humana (=individuo-en-relación) tiene necesidad de estas esferas de relacionalidad. Los llamados «movimientos social es» son el terreno en el que nacen y se desarrollan los «sujetos» del tercer sector que encarnan estas necesidades de la relacionalidad humana.

En síntesis, obervar el tercer sector y sus organizaciones - en cuanto nuevos sujetos sociales- significa acceder a una nueva visión de la sociedad que no la describe ni como agregado de individuos, ni como mero flujo de comunicaciones, ni como el hacer de sistemas autopoiéticos, ni como pura dinámica simbólica, sino como una realidad relacional, hecha de relaciones (o redes) que conectan actores intersubjetiva y estructural mente. 
modalidades de especificación, presentaré al gunas propuestas tipológicas, una de ellas particularmente atenta a los procesos de cambio a través de los que la organización produce nuevas formas y posibilidades operativas, pero, simultáneamente, también conflictos y tensiones. En síntesis, trataré de obtener de la reseña tipológica aquéllas que considero que poseen las principales distinciones directrices ${ }^{4}$, esto es, los elementos que hacen que una organización sea o no sea referible al tercer sector.

\section{Variedad y diferencia en las organizaciones del tercer sector}

En un reciente estudio sobre la eficiencia de las organizaciones del tercer sector italianas, M. Ambrosini (1994) enunciaba como rasgos distintivos de este tipo de organizaciones:

a) Las actividades realizadas son variadís mas junto a las actividades de pura asistencia o cuidado, en muchos casos también realizadas por organizaciones públicas, encontramos actividades comerciales del todo similares a las normalmente realizadas por empresas de mercado. El sociólogo italiano agrupa esta variedad en cinco grandes sectores de intervención: el sector socioasistencial, el de la educación y la animación cultural, el de la defensa ambiental y el de la protección civil 5 .

b) La misma variabilidad vale para las dimensiones: aunque la mayoría de las organizaciones poseen entradas modestas, ningún trabajador pagado y grupos pequeños de voluntarios, existe una minoría de organizaciones muy estructuradas que se basan en grandes budgets, en un staff profesional muy amplio y articulado, además de en millares de voluntarios.

c) Las fuentes de ingresos están diversificadas, no sólo desde el punto de vista de la cantidad, sino también con respecto a la procedencia. D ejando a un lado la primera ramificación, si se excluyen las ganancias derivadas de una oculta gestión financiera, las principales fuentes de financiación de las organizaciones del tercer sector pueden ser agrupadas en:

- Ingresos procedentes del sector público. Internamente, esta fuente de financiación se articula en dos secciones: financiación directa y financiación

4. La noción de distinción directriz ha sido elaborada por N . Luhmann (1984), (1990).

5. En mi opinión, en cuanto que la óptica dominante desde la que se observa al tercer sector aún es una óptica «moderna» - en la que estas organizaciones se explican como resultado de los «fracasos» del Estado o del mercado, por tanto se trata de observaciones externas al tercer sector que lo definen en negativo y por exclusión: aquello que no es ni Estado, ni mercado (B. Weisbrod, 1988; H. B. H ansmann, 1987) - , la existencia de estas actividades Ileva a más de uno a exlcuir a estas organizaciones del tercer sector (P. O 'M alley, 1983), o bien a acusarlas de ejercer una competencia desleal con respecto a las empresas de mercado, ya que gracias a la legislación vigente gozan de tratos fiscales de favor (W. Seibel, 1989, 1990). 
indirecta. En el ámbito de la primera modalidad (directa) encontramos los dos principales instrumentos de soporte y apoyo a disposición del sector público para promover y promocionar las organizaciones del tercer sector: el sistema de las contribuciones y de las subvenciones (grants) y el sistema de la convenciones (contracts). La segunda forma de financiación (indirecta) comprende:

1. El conjunto de medidas encaminadas a conferir un estatus de exención (total o parcial) a la actividad y al patrimonio de la organización.

2. La atribución de la posibilidad de deducir del propio ingreso imponible, por parte de aquéllos que ofrecen las contribuciones económicas, de todo o parte de la suma donada.

C ada una de las formas de financiación pública mencionadas obliga a las organizaciones del tercer sector al cumplimiento de una serie de condiciones, a veces muy rigurosas en términos de procedimientos administrativos a seguir, de estándar a respuestas, que inciden fuertemente en la gestión y en la financiación de estas organizaciones.

- Ingresos prodecentes de la venta de bienes y servicios. Consiste en dos actividades diversas: a) el eventual recargo monetario de los servicios distribuidos en la consecución del propio fin asociativo (estatutario); b) las entradas derivadas de la realización de actividades comerciales marginales (que deben tener o poseer un carácter secundario en la organización y, si se quieren beneficiar de las exenciones fiscales eventualmente previstas, deben ser completamente invertidas en la organización con el fin de mejorar la capacidad de consecución de los fines vigentes en los estatutos).

- Ingresos procedentes de las donaciones Probablemente constituye la fuente de financiación más característica de las organizaciones del tercer sector: aquélla que más las distingue de las empresas de mercado y de las agencias públicas. Las donaciones pueden tener su origen en dos tipos de actores:

a) individuos particulares (ciudadanos contribuyentes y familias);

b) entes e instituciones (fundaciones, empresas comerciales, bancos, etc.).

Respecto al peso de las contribuciones procedentes de tales sujetos, las investigaciones empíricas y las indagaciones socioeconómicas han invalidado una imagen que se había venido consolidando a lo largo del tiempo: la mayor parte de los ingresos procedentes de donaciones tienen su origen en entes, empresas e instituciones. 0 curre totalmente lo contrario, las donaciones proceden en su mayor parte y peso de apor- 
taciones de millones de comunes ciudadanos pertenecientes en su mayoría a clases medias y medio-bajas de la población ${ }^{6}$.

D esde el punto de vista de la gestión, esta fuente requiere el desarrollo, de manera sistemática, de las relaciones públicas y de «marketing», y la utilización de diversas técnicas de recogida de fondos (fund-raising).

- Ingresos procedentes de las cuotas asociativas. Se trata de una forma tradicional de financiación que no requiere la utilización de técnicas y mecanismos de gestión particularmente sofisticados. $M$ ás bien se debe desarrollar una política de marketing interno, es decir de atención a los propios miembros; éstos deben ser vistos y tratados como verdaderos y propios «clientes» de la organización?. La demostración de una capacidad de escucha (atención a las sugerencias procedentes de los socios), de voluntad para poner en práctica las acciones prometidas, además de la adopción de una modalidad de gestión participativa, son elementos que refuerzan el clima motivacional de la organización y, con ello, el sentido de pertenencia de los miembros singulares 8 . Si se excluyen aquellas organizaciones de reducidas dimensiones, esta fuente de financiación está asumiento un rol cada día más marginal en el interior de las fuentes de financiación de las organizaciones del tercer sector. Su puesto está siendo ocupado por las entradas derivadas de la venta de servicios a los usuarios y de los ingresos procedentes de la utilización de técnicas de recogida de fondos si empre más sofisticadas?.

d) Algunas organizaciones operan sistemáticamente en colaboración con el sector público/estatal, mientras que otras actúan de manera completamente autónoma. Recuerdo que con el término contrating-out se hace referencia a una práctica ampliamente generalizada en todos los sistemas de welfare avanzados, pero que recientemente ha sido sometida a un proceso de aceleración. Se trata de la compra de la elaboración de bienes y servicios por parte del ente público, que ve en las organizaciones singulares un actor privilegiado.

Los aspectos de gestión y organizativos que pone en escena el contrating-out son numerosos y van a incidir, en un futuro no muy lejano, en la configuración de este tipo de organizaciones. En primer lugar, nos encontramos con el efecto positivo de poder contar, durante un período

6. Véanse J. Kendall, M. Knapp (1990); A. Ardigo (1992); L. Salamon, H. Anheier (1992); R. Bauer (1993); W. M eleief (1994); Perri 6 (1994); I. ColozzI, A. Bassi (1995);

P. DONATI (1996).

7. L. W. KENNEDY (1991).

8. L. BOCCACIN (1995).

9. Véanse D. Easley, M. O 'H ara (1983); M. L. Phelan (1987); O. Chillemi (1989); A. W AGNER (1990); B. GUI (1990). Todo esto requeriría una mayor puntualización en función de las diversas configuraciones nacional es del tercer sector. Por razones de espacio, dicho tema no puede ser afrontado con más profundidad. 
estable de tiempo, con unos ingresos seguros (efecto de estabilización). Ello va a permitir el no tener que invertir una cantidad notable de energías (humanas y organizativas) en la búsqueda de recursos económicos. Existe la posibilidad de que las organizaciones del tercer sector puedan realizar políticas y proyectos de amplio respiro, de medio y largo período, y no tener que estar, en consecuencia, obligadas a adoptar estrategias de «navegación a la vista». En segundo lugar, nos encontramos con los costes administrativos ligados al proceso de presentación de la oferta, de preparación de un proyecto detallado que comprenda una prevención económica, de preparación de la documentación periódicamente pedida por el ente público para valorar el respeto de los estándares cuantitativos y cualitativos fijados ${ }^{10}$.

D esde el punto de vista del management, posiblemente el aspecto más importante ligado a la utilización de la financiación pública es la gestión del flujo de caja (cash-flow). El sistema de pagos de la Administración pública se basa en un principio ex post, es decir, en la cobertura de los costes ya sostenidos, tras la presentación de facturas (en el caso de los conciertos con cooperativas sociales) o de reembol sos hechos, tras la presentación de justificantes (en el caso de los conciertos con organizaciones de voluntariado). Todo ello obliga a este tipo de organizaciones a realizar fuertes desembolsos, como anticipación de gastos (administrativos, de personal, para la adquisición de material, etc.) que sólo serán cubiertos en una fase sucesiva (de duración variable). Esta continua necesidad/carencia de capital circular obliga a las organizaciones del tercer sector a pedir préstamos a bancos y agencias de crédito, con notables costes financieros (intereses pasivos sobre préstamos). La oculta gestión y administración del cash-flow se convierte, en consecuencia, en uno de los objetivos principales de los directivos de estas organizaciones. No olvidemos que una parte importante de sus ingresos para la elaboración de servicios proviene de los conciertos con entes públicos ${ }^{11}$.

e) La inscripción o no en los registros vigentes crea importantes diferencias en el plano del estatus jurídico y de los tratos fiscales y contributivos. Todas estas diferencias tienen obvias implicaciones desde el punto de vista del management organizativo. Dirigir cinco personas es diferente de dirigir quinientos; gestionar una organización con centenares de voluntarios part-time que no reciben dinero es diverso del gestionar una organización compuesta entera, o prevalentemente, por personal profesional retribuido. Gestionar una organización cuyas entradas dependen enteramente de donaciones de la población, en buena medida inciertas e impredecibles, es diferente de gestionar una organización que puede contar con fondos públicos. G estionar una oferta de servicios es diverso que gestionar una actividad de sensibili- 
zación a un problema o un pequeño grupo de self-help que no quiere ni siquiera sentir la palabra gestión.

Tras este recorrido por algunos de los rasgos que ponen de manifiesto la diferenciación de las organizaciones del tercer sector, no es aventurado afirmar que tal tipo de organizaciones se ha convertido, en la Europa de fines del segundo milenio, en un modo generalizable para producir bienes y servicios de tipo material o inmaterial, para los que las formas y contenidos de estas organizaciones pueden cambiar: bien sea en relación con el tipo de bien/servicio que producen y con las características de los otros sujetos que operan en el mismo sector, bien sea en relación con los procesos de morfogénesis social12.

A pesar del amplio espectro de sujetos organizativos y de prácticas operativas que constituyen el núcleo central de aquella esfera de actividades denominada tercer sector en el contexto de las formaciones sociales del 0 ccidente industrializado, entre los estudiosos de management y los managers de este tipo de organizaciones existe un común acuerdo en definirlas como un tipo de orga nizaciones cuyo objetivo es algo diverso del producir un beneficio para los propietarios: el fin último es elaborar servicios. D esde esta definición se deriva también la característica principal que diferencia las organizaciones del tercer sector de las empresas de mercado: mientras que en éstas últimas el objetivo de los directivos es maximizar el beneficio, en las organizaciones del tercer sector las decisiones tomadas por el management están encaminadas a asegurar la elaboración del mejor servicio posible en función de los recursos disponibles; para las empresas de mercado el éxito viene dado por el incremento de los beneficios, en las organizaciones del tercer sector el éxito principalmente es medido en los términos de «cuantos» servicios produce la organización y el «modo en que» estos servicios vienen distribuidos. Partiendo de este potulado genérico, especialmente interesantes resultan los indicadores elaborados por D . L eat para medir el éxito de las organizaciones del tercer sector:

- Capacidad de innovación y experimentación.

- Ser un instrumento para ampliar las oportunidades de elección de al gunas capas de la población.

- Ser un vehículo para la participación de los usuarios en el proceso de decisiones y en el control sobre la cantidad y la calidad de los servicios.

- La estructura de las fuentes de financiación.

- El clima organizativo interno y las modalidades de gestión de los voluntarios y del personal dependiente.

- La oferta de formación cualificada.

- Las relaciones de redes con otros sujetos del tercer sector y la capacidad de dar vida a nuevos organismos ${ }^{13}$.

12. Véase G. Charmet (1985); P. D onati (1984); A. EtzIONI (1988); B. Catarin ussi (1994); G. LAZZARINI (1991).

13. Véase D. LeAT (1994). 
Tomando como punto de partida estas premisas, una serie de estudios e investigaciones han tratado de evidenciar las características del proceso productivo de las organizaciones del tercer sector y de los sistemas de control de la gestión utilizados. El fin era poner de manifiesto los puntos de fuerza y de debilidad.

R.N . Anthony y D.W. Young (1990) han intentado individuar las peculiaridades de este universo organizativo, peculiaridades que dejarían sentir su influencia en el proceso de control de la gestión. Éstas pueden quedar sintetizas en el siguiente elenco:

- ausencia de una medida de beneficio;

- diverso estatus legal y fiscal;

- tendencia a ser organizaciones que producen servicios;

- mayores límites en los objetivos y en las estrategias;

- menor dependencia de la clientela para el apoyo financiero;

- dominio de profesionales (médicos, abogados, enfermeros, asistentes sociales);

- diferencias en el modo de gobierno;

- diferencias en el management;

- peculiar importancia de la influencia política;

- persistencia de un uso inadecuado de los sistemas de control de la gestión.

Este conjunto de peculiaridades se agruparían así:

a) Las características técnicas.

b) Las características operativas o comportamentales.

El primer grupo comprende aquellas cuestiones referentes a la ausencia del beneficio como medida de las prestaciones realizadas por la organización. El segundo agrupa todos los otros aspectos. La principal conclusión que se puede extraer es la siguiente: «la no existencia de una singular, suficiente, y general medida de las prestaciones que sea comparable al criterio del beneficio de las empresas de mercado (es decir, la dificultad de medir los output y la relación entre input y output), constituye un fuerte obstaculo que impide el desarrollo de eficaces sistemas de control de la gestión en las organizaciones del tercer sector».

Siempre según estos autores, en cuanto unidad de medida, el beneficio permite las siguientes prestaciones:

1. Elaborar un criterio singular que puede ser usado para valorar cursos de acción alternativa.

2. Realizar un análisis cuantitativo de estas alternativas a partir del cual los beneficios pueden ser directamente comparados con los costes.

3. Forjar una única y amplia medida de las prestaciones.

4. Permitir la descentralización de las funciones de dirección y de gestión. 
5. Facilitar la comparación de la prestación entre unidades que desarrollan funciones diversas.

P. F. D rucker, en un reciente volumen sobre la gestión en las organizaciones del tercer sector, profundiza en las características que diferencian a estas orga nizaciones de las empresas comerciales y de las agencias estatal es ${ }^{14}$. Subraya el hecho de que las organizaciones del tercer sector hacen y realizan algo sustancialmente diferente de lo hecho y realizado por éstas últimas. Su producto no está constituido ni desde un bien, ni desde una ley o reglamento, sino más bien por el cambio de una persona (un ser humano). Son instituciones que procesan personas en cuanto agentes de cambio. D e aquí se deriva el hecho de que las organizaciones del tercer sector no puedan eludir el adoptar técnicas de management como han hecho hasta ahora, sino que, al contrario, tienen necesidad de éstas en mayor medida que las empresas de mercado a fin de conseguir, de la mejor manera posible, su mission (objetivo principal, fin último).

P. C. N utt y R. W. Backoff individuan en la categoría del «ser público» (publicness = grado de publicidad) el trato distintivo de estas organizaciones respecto a las mercantiles ${ }^{15}$. El hecho de estar sometidas sus operaciones a influencias y controles por parte de la autoridad pública, el elevado grado de visibilidad pública de sus operaciones, el tener que dar cuenta de sus operaciones en última instancia a la comunidad donde actúan, hace que las organizaciones del tercer sector sean organizaciones sui generis (con un nivel medio de publicness, entre el máximo del Estado y el mínimo de las empresas con fines de lucro). Ello tiene notables repercusiones en sus procesos organizativos y, por tanto, en los instrumentos de gestión utilizables.

T. H. Jeavons - estudioso americano de la historia del tercer sector, con particular atención a las organizaciones religiosas- subraya como característica fundamental de las organizaciones del tercer sector el hecho de ser organizaciones «expresi vas de valores»16. Esto implica que el «modo» en que actúan el «tipo de relaciones» que circulan está íntimamente conectado a los val ores que tales organizaciones representan. Surge, en consecuencia, el problema de como es posible definir y valorar la eficacia de organizaciones que son, al mismo tiempo, «instrumentos de testimonio y agencias productoras de servicios». Ello influye tanto en las modalidades de realización de las campañas de recogida de fondos (el mensaje que se transmite debe ser veraz), como en la gestión de los recursos humanos (todos los miembros de la organización, sea cual sea el rol cubierto, deben ser tratados según una al ta concepción de las relaciones personales y una atención por el desarrollo de la persona).

En un estudio sobre la función de gobierno en las organizaciones del tercer sector, M. M iddleton individua tres características de base que influyen en la actuación de los consejos de administración: 
1. A menudo sus objetivos son ambiguos, de difícil cuantificación y abiertos a una pluralidad de interpretaciones.

2. Con frecuencia las organizaciones del tercer sector están sujetas a solicitudes conflictivas dirigidas por diversos grupos sociales, por ejemplo, los donantes-financiadores y los clientes-usuarios.

3. En buena medida estas organizaciones confían en networks interpersonales con el fin de facilitar los flujos de recursos hacia y por parte de la organización 17 .

Sobre este aspecto de la multipleconstituency de las organizaciones del tercer sector se centran R. M oss K anter y D. V. Summers en un estudio sobre los dilemas de medición de la performance de estas organizaciones ${ }^{18}$. Según estos autores, es la centralidad de los valores sociales, respecto a los financie ros, lo que complica la medición en las organizaciones del tercer sector. Para éstas, los tests de buen funcionamiento deben ser diversos en cuanto que no se definen en torno a la ganancia financiera, sino en torno a la mission y a los servicios que ofrecen. El hecho de poseer una multiplicidad de sujetos sociales (consituency), respecto a los que tienen resposabilidades (accountability) introduce una complejidad posterior. Ahora bien, sólo reconociendo y teniendo en cuenta la pluralidad y diversidad de fuerzas y de sujetos que actúan en el interior y en exterior de todas las organizaciones del tercer sector, es posible definir niveles satisfactorios de prestaciones (estándar) respecto a valorar sus actuaciones.

Basándose en los resultados de una investigación sobre trescientas organizaciones del tercer sector - que actúan en el campo de los servicios sociales y sanitarios de algunos Estados del este de los EE.UU - - , C. D . M cC auley y M .W. H ughes (1993) lograron individuar una serie de desafíos que los managers de este tipo de organizaciones tenían que afrontar (tabla 1).

La utilidad del esquema consiste en permitir la inmediata individuación de las características organizativas y de gestión propias de las organizaciones del tercer sector, independientemente de las que presentan las empresas de mercado o las agencias públicas. Si bien los primeros seis desafíos (o requisitos), que asumen una manifestación específica en las organizaciones del tercer sector son comunes a las organizaciones que actúan en otros sectores, el segundo grupo (7 al 12) es típico, y en cierto modo exclusivo, de esta tipología organizativa.

Sólo en las organizaciones del tercer sector la relación entre el manager y el consejo de administración asume un carácter paradójico (70 desafío). En cuanto que no puede fundarse en una clara relación entre propietarios (accionistas) y dependientes (dirigentes), asumen una especial importancia los elementos ideológicos, de estatus, de clase, de pertenencia, que dan lugar a un equilibrio inestable.

17. Véase M. MIDDLETON (1987).

18. Véase R. M oss, D. V. SUM M ERS (1987). 
Tabla 1. D esafíos que deben afrontar los managers de las organizaciones del tercer sector.

1. Utilización de recursos y predisposición de apoyos para el cambio.

2. Dirigir y motivar al personal.

3. Construcción de un apoyo externo y difusión del conocimiento de la propia organización.

4. M ejoras de las prestaciones de la propia organización.

5. Presión temporal.

6. Falta de un ambiente de trabajo estimulante.
7. Conflictos con el consejo de administración.

8. Problemas con los clientes/usuarios y con grupos externos.

9. Integración de peticiones divergentes.

10. Recursos limitados e inciertos.

11. Presencia de voluntarios.

12. Falta de conocimiento managerial, experiencia.

O tra característica de las organizaciones del tercer sector es tener una multiplicidad de sujetos (constituency) que pueden hacer valer su posición en la evolución de la gestión de la organización ( 8 o desafío).

Al tener que rendir cuentas públicamente (publicness), este tipo de organizaciones debe operar bajo la presión continua de grupos externos. Éstos últimos someten a un constante examen las decisiones políticas y, a veces, presentan sugerencias inconciliables ( 9 o desafío).

No existe ninguna duda en torno al hecho de que, si son comparadas con otro tipo de organizaciones, las modalidades operativas del tercer sector presentan una incerteza y limitación con respecto a los recursos económicos y financieros ( $10^{\circ}$ desafío). La situación se agrava por tener que depender, de manera significativa, de las contribuciones de otros sujetos públicos (entes y administraciones locales) y privados (empresas y ciudadanos particulares), cuya fiabilidad y continuidad en el tiempo está fuera de la capacidad de control de la organización. O tro elemento diferenciador de las organizaciones del tercer sector es la presencia de un el evado número de personal voluntario. Se trata de un elemento ambivalente. Por un lado, puede constituir una ventaja competitiva respecto, por ejemplo, a las empresas de mercado, por otro, conlleva numerosos problemas de gestión. Por parte del manager, la presencia de voluntarios requiere un esfuerzo y una atención mayores que los que presenta el personal contratado, bien sea por su participación a tiempo parcial, bien sea por la necesidad de tener que reforzar continuamente sus motivaciones (11ํㅡㄹ desafío). Para terminar, los directivos de las organizaciones del tercer sector suelen poseer un nivel más bien bajo de conocimientos y de utilización de técnicas de gestión, máxime si tomamos como medida comparativa sus colegas de las empresas de mercado. Sobre este particular, resulta especialmente interesante indagar en las carreras profesionales de las 
que proceden. Generalmente suelen ser carreras específicas (médicos, asistentes sociales) con poca o ninguna experiencia en el mundo de la gestión (12ำ desafío).

Concluyendo, a partir de la literatura examinada emergen dos elementos que, en mi opinión, determinan el carácter específico de las organizaciones del tercer sector:

1. La ausencia de una unidad de medida general, comparable al resultado económico en las empresas con fines de lucro.

2. El estar gobernadas desde (directa, centradas en) la mission.

\section{Tipos de organizaciones del tercer sector}

En cuanto que bajo la categoría «organizaciones del tercer sector» se agrupan y engloban diferencias consistentes, ¿es posible distinguir y especificar entre ellas al menos por tipos?

Para dar respuesta a este interrogante se han realizado diversos intentos, pero los resultados no son plenamente satisfactorios. En parte, el problema es debido al hecho de que las tipologías sirven para objetivos diversos: un determinado conjunto de distinciones, por tanto, es satisfactorio respecto a un cierto uso y no satisfactorio para un uso diverso.

0 tra dificultad para encontrar una tipología de las organizaciones del tercer sector satiffactoria depende de la natural eza misma del objeto, éste tiende a eludir toda categorización neta y a ubicarse siempre en los cabalgamientos de los confines. A pesar de todo ello, me parece oportuno dedicar unas líneas al análisis de las tipologías disponibles: dan luz a al gunas de las características clave de las organizaciones del tercer sector y algunas distinciones son útiles para entender la especificidad organizativa.

Ti pologías por fuentes de financiación y de control. Prestando una especial atención a los aspectos económicos que caracterizan al área del tercer sector, H. B. H ansmann ha elaborado una tipología que considera las modalidades de financiación y de control de estas organizaciones ${ }^{19}$. Por lo que respecta a la financiación, en el interior del área del tercer sector es posible distinguir dos categorías: las organizaciones fundadas en las donaciones (donative), que se nutren principalmente de subvenciones y contribuciones privadas y, en menor medida, de financiaciones públicas, y organizaciones fundadas en las ventas (commercial), es decir, aquéllas cuyos ingresos proceden de la venta de servicios a los usuarios. En cuanto a las formas de control de las organizaciones, $\mathrm{H}$ ansmann distingue: organizaciones controladas por los que ofrecen las donaciones (mutual) y organizaciones de tipo empresarial (entrepreneurial), en las que funciona un consejo de administración no ligado a las figuras de los benefactores. 
Tabla 2. Tipología de H ansmann de las organizaciones non profit.

\begin{tabular}{lll}
\hline & $\begin{array}{l}\text { O rganizaciones controladas } \\
\text { por los donantes }\end{array}$ & Organizaciones empresariales \\
\cline { 2 - 3 } $\begin{array}{l}\text { O rganizaciones } \\
\text { fundadas sobre } \\
\text { donaciones }\end{array}$ & Clubs políticos & M useos de arte \\
$\begin{array}{l}\text { Organizaciones } \\
\text { fundadas sobre } \\
\text { las ventas }\end{array}$ & Uniones de consumidores & Casas de descanso y reposo \\
\hline
\end{tabular}

Fuente: H.B. H ansmann (1987).

D e estas dos categorías derivan cuatro diferentes tipos de organizaciones de tercer sector (véase tabla 2). En el interior de cada una de estas cuatro casillas se ha ubicado un ejemplo de organización de tercer sector que se engloba en aquella determinada tipología.

Elaborando posteriormente esta tipología y cruzando entre sí las categorías que se derivan, $\mathrm{H}$ ansmann propone una tipología articulada sobre cuatro niveles: 1. las organizaciones de tercer sector mutualistas; 2 . las organizaciones de tercer sector empresariales; 3 . las organizaci ones de tercer sector donati vas; 4. las organizaciones de tercer sector de venta mutualista.

Las primeras (mutualistas) distribuyen bienes y servicios exclusivamente en su interior, las organizaciones de tercer sector empresariales tienen una audiencia potencialmente indiferenciada, las organizaciones de tercer sector donativas se comprometen en acciones de beneficencia de tipo tradicional, las organizaciones de tercer sector de venta mutualista representan una forma mixta en la que se combinan - en la distribución de bienes y servicios- características comercial es y aspectos filantrópicos.

A través de esta tipología analítica, $\mathrm{H}$ ansmann pone de relieve la preferencia del consumidor por las organizaciones sin fines de lucro en los casos en queel mercado no es lo sufici entemente transparente como para garantizar un control sobre la calidad del producto o del servicio ofertado mediante tradicionales contratos comerciales. Bajo este aspecto, las organizaciones de tercer sector se presentarían más competitivas en torno a la oferta de garantías. Instaurarían con el consumidor un «contrato de confianza» fundado en el vínculo de la no distribución de los beneficios y, por consiguiente, en la falta de incentivos a la acumulación de los mismos²0.

En esta perspectiva se ubica la interpetación de B. Gui: clasifica las organizaciones productivas de bienes y servicios respecto a los criterios de «categoría beneficiaria» y «categoría dominante». El primero identifica a aquéllos que, por designación de los estatutos, ocupan una posición de ventaja, bien a través de precios a favor o bien a través de servicios mejores. El segundo cri- 
Tabla 3. Clasificadión de las organizadiones.

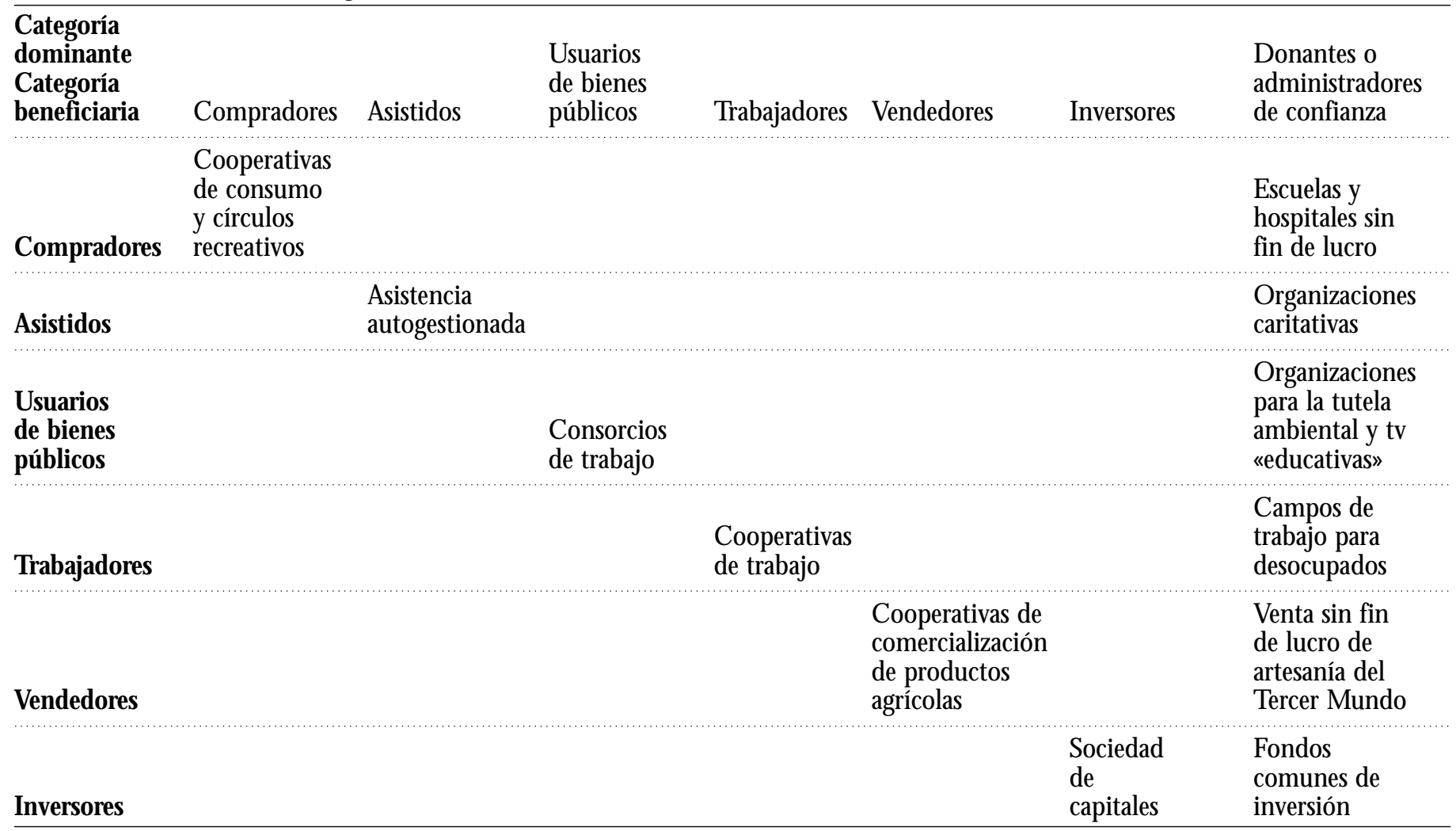

Fuente: B. Gui (1990). 
terio individua al grupo de sujetos que, en función de los estatutos, le es asignado el poder decisorio sobre la organización 21 . Utilizando estos dos criterios de clasificación, Gui propone la tabla 3.

Ti pologías basadas en las actividades. O tras tipologías útiles para clasificar las organizaciones del tercer sector se centran en las actividades desarrolladas. Este criterio, que ha sido recogido en la legislación americana ( $N$ ew York N onfor-profit Corporation Law, 1970; California's N ew N onprofit Corporation Law, 1980), identifica cuatro áreas privilegiadas de intervención: el área de la salud, de la educación, de los servicios social es y de las organizaciones religiosas. Tomando las características estructural es es posible agrupar las organizaciones del tercer sector que desarrollan sus acciones dentro de estos campos en cuatro categorías:

1. Charitable nonprofit organization. Representa a aquellas organizaciones filantrópicas de tipo tradicional.

2. Social nonprofit organization. Comprende organizaciones que poseen objetivos «caritativos, educativos, religiosos, científicos y cultural es» (N on-forProfit Corporation Law, 1970).

3. Political nonprofit organization. $\mathrm{H}$ ace referencia a aquellas organizaciones que desarrollan planteamientos comerciales con el fin de perseguir objetivos públicos o casi públicos²2.

4. Trade nonprofit organization. Engloba a aquellas organizaciones que poseen objetivos de tipo comercial no lucrativo.

Permaneciendo dentro del ámbito de las actividades desarrolladas, la siguiente tipología identificada por B. Weisbrod tiene el objetivo de clasificar analíticamente las organizaciones del tercer sector de carácter social. El estudioso americano individua una gama articulada de servicios de tipo social realizados por organizaciones sin fines lucrativos (agrupados en veintidós categorías ${ }^{23}$ ), que se extiende desde los servicios de comunidad, a las organizaciones de rehabilitación y asistencia a enfermos, a las ayudas a grupos marginales, a las acciones para campañas preventivas y de presión, etc.

21. Véase G. GuI (1990).

22. Véase H. L. O LECK, 1980).

23. 1. Religious Activities, 2. Schools, Colleges and Related Activities, 3. Cultural, H istorical or $O$ ther Educational Activities, 4. O ther instruction and Taining Activities, 5. H ealth Services Related Activities, 6. Scientific Research Activities, 7. Business and Profesional O rganizations, 8. Farming and Related Activities, 9. M utual O rganizations, 10. Employee or M embership Benefit O rganizations, 11. Sports, Athletic, Recreational and Social Activities, 12. Youth Activities, 13. Conservation, Environmental and Beautification Activities, 14. Housing Activities, 15. Inmer City or Community Activities, 16. Civil Rights Activities, 17. Litigation and Legal Aid Activities, 18. Legislative and Political Activities, 19. Advocacy, 20. O ther Activities Directed to Individuals, 21. Activities D irected to 0 ther $O$ rganizations, 22. 0 ther Purpose and Activities. Véase B. Weisbrod (1980). 
Un conjunto así de amplio y heterogéneo de iniciativas puede ser diferenciado según dos líneas directrices:

a) O rganizaciones que producen bienes y servicios de utilidad pública (collective goods) ${ }^{24}$.

b) O rganizaciones que producen bienes y servicios a beneficio exclusivo de los propios miembros (mutual ben efit organizations) ${ }^{25}$.

Las organizaciones del tercer sector de «mutua-ayuda» ofrecen servicios de uso exclusivo interno, no tienen necesariamente una utilidad social (sirvan de ejemplo los clubs o las asociaciones de categoría): en tales organizaciones no existe conflicto de intereses individuales y colectivos desde el momento en que el objetivo de la acción social es la tutela (o la consecución) del bienestar privado de los propios miembros. De forma análoga, B. G ui sugiere distinguir entre organizaciones mutualistas (mutual benefit), caracterizadas por la coincidencia entre categoría beneficiaria y categoría dominante, y organizaciones «sin fines de lucro en sentido estricto» (public benefit), caracterizadas por la asignación del poder decisorio a sujetos que no estarían económicamente interesados en las actividades de la organización. De cuanto se ha dicho se obtiene la siguiente visión de tercer sector: «área constituida por organizaciones formales privadas gestionadas por estatutos que favorecen a categorías diversas de los que aportan el capital, y caracterizada por una incompleta apropiación del valor de empresa por parte de quien ejerce el poder decisorio»26.

Esta clasificación es posteriormente aclarada en la tabla 3, relativa a la clasificación de las organizaciones: en ella, las casillas significativas se sitúan en la diagonal principal (organizaciones mutualistas) y en la última columna (organizaciones sin fines de lucro en sentido estricto).

Por tanto, en el interior de las estructuras que elaboran collective goods, parece que es posible revisar el nucleo distintivo del tercer sector, en torno al que se ubican iniciativas diferentes, como en el caso de las mutual ben efit organizations. Éstas últimas, sin embargo, en su interior contienen, en mayor o menor medida, los rasgos de una acción no por beneficio relevante socialmente.

Ti pologías basadas en las finalidades. En el lenguaje organizativo, la finalidad o el objetivo principal de la organización se expresa con el término mission. Rose ha sugerido la existencia de sólo dos tipos de asociaciones voluntarias o nonprofit: los grupos expresivos y las asociaciones de influencia27. Los primeros actúan para expresar o satisfacer intereses propios de los miembros. Las asociaciones de influencia, sin embargo, concentran sus esfuerzos en la sociedad para provocar cualquier cambio o una condición que retienen como positiva.

24. Véase B. W EISBROd (1980), (1988).

25. Véase B. I. BitTKeR, G. K. RAhdert (1976).

26. Véase B. GuI (1990).

27. V éase A. RoSE (1967). 
Aunque la distinción parece neta y simple, ilumina una diferencia fundamental entre organizaciones que miran «fuera» y organizaciones que miran «dentro». Una distinción más útil en esta dirección es la desarrollada por Gordon y Babchuk entre organizaciones expresivas e instrumental es. Las organizaciones expresi vas existen, primariamente, para expresar y satisfacer los intereses de los miembros, mientras que las organizaciones instrumentales quieren, por regla general, hacer cosas para los otros y/o con los otros. Las organizaciones expresivas tienen fines internos, las instrumentales, externos 28.

C on posterioridad, estos autores han introducido otra categoría: organizaci ones «non pr ofit» instrumentales expresivas. Este tercer tipo nace del reconocimiento de que la tipología binaria es excesivamente simplificadora, mientras que muchas organizaciones parecen tener ambas finalidades. Por ejemplo, una organización de voluntariado puede tener un objetivo instrumental y estar organizada, en consecuencia, a nivel nacional, pero, a nivel local, puede tener esencial mente una función expresiva para los voluntarios.

En un reciente estudio sobre el tercer sector en Italia, P. D onati y G. R ossi elaboran una tipología que distingue las organizaciones de este nuevo tertium de la escena social a lo largo de dos ejes:

1. Según el tipo de servicios producidos (preval entemente de tipo particular y específico, o bien general y difuso).

2. Según el tipo de destinatarios (prevalentemente internos, los socios, o externos, terceros) 29 .

En mi opinión, con la introducción de la distinción de los servicios producidos, en buena medida se superan los peligros reduccionistas de una tipología binaria centrada en lo interno o lo externo, así como también se da una mayor claridad a los intentos mixtos (organizaciones instrumentales-expresi vas) anteriormente mencionados.

Cruzando los dos ejes, los sociólogos italianos distinguen cuatro tipos emblemáticos:

1. Producción de servicios particulares para los socios. Se trata de organizaciones del tipo autoayuda (por ejemplo: redes de familias con alcohólicos que practican formas de self-help) y ayuda mutua o ayuda recíproca (por ejemplo: redes de familias y vecinos con hijos en dificultad, o ancianos, que se intercambian servicios recíprocos y otras formas de mutual help).

2. Producción de servicios particulares para soci os y no socios, por tanto, con apertura al exterior. Se trata de organizaciones que realizan una obra cooperativa prosocial (por ejemplo, bajo la forma de cooperativas de solidaridad social), con la producción de servicios y bienes particulares (servicios personales) dirigidos principal mente a terceros. 
3. Producción de servicios generales para los soci os. Se trata de organizaciones que promueven, organizan y gestionan servicios de «privado social »30 para hacer frente a necesidades de tipo general (no particular) difundidas en la comunidad (por ejemplo, la educación o la atención médica). Buena muestra de ello serían aquellas organizaciones formadas por padres que establecen escuelas no de ben eficio, destinadas en primer lugar a los socios. Se trata de formas organizativas que tienen utilidad pública en cuanto que el servicio producido es de tipo general (como la instrucción, una visita médica 0 un examen clínico), aunque primariamente - pero no de forma exclusiva- esté dirigido al interior de la organización (es decir, a los socios, socios que pueden ser todos aquellos que lo deseen).

4. Producción de acci ones y servi cios generalizados para un destinatario público. Se trata de organizaciones de carácter universal, bien por la organización de servicios de privado social accesibles a todos (socios y no socios), bien por la persecución de fines culturales, de opinión o de derecho político; por ejemplo: organizaciones que promueven respuestas educativas a las necesidades de los estudiantes de un determinado orden de escuela (en el amplio campo del derecho al estudio); o bien el caso de «sindicatos de familias» que tienen como finalidad el sensibilizar a la opinión pública y a la clase política sobre un determinado problema; en este tipo se engloban las asociaciones de tutela y defensa de los derechos sociales (advocacy), las asociaciones para la defensa del enfermo, de los usuarios de ciertos servicios, etc.

Esta tipología sobre todo sirve para poner luz sobre aquellas funciones relevantes que no pueden ser absorvidas por otros actores de la sociedad. Aún cuando algunas finalidades pueden converger con otros actores, incluso el Estado, éstos últimos no pueden sustituir a las organizaciones de tercer sector, ya que expresan y actúan derechos propios. La tipología también evidencia como las organizaciones de tercer sector pueden combinar la producción de servicios y bienes particulares/general es hacia el interior o el exterior de diversas formas, pero siempre relacionadas con las necesidades de un «Alter» que viene representado como organización.

30. Con el término privado social, D onati individua y agrupa formas sociales de gestión autónoma de producción y participación (por ejemplo, formas mixtas, asociaciones, grupos primarios y secundarios), que actúan tanto en el ámbito económico, como en el de los sistemas sociales. El autor se ubica explícitamente contra las teorías de la modernidad que leen la dinámica interna de las sociedades complejas como dialéctica entre los polos del Estado y el mercado. Reivindica (con el auxilio de numerosos recursos empíricos) la permanencia y la morfogénesis (también en formaciones sociales con elevada contingencia y diferenciación funcional) de formas de relaciones sociales que 1) no son ni públicas ni privadas; 2) están reguladas por un propio código simbólico-normativo y tienen medios propios generalizados de intercambio; 3 ) están caracterizadas por una subjetividad social propia; 4) se desarrollan en proporción al tipo y nivel de complejidad. V éase P. D onati $(1978,1991$, 1993, 1996). 
Tabla 4. Tipología de las organizaciones según el tipo de servicios producidos (de tipo particular o general) y según los destinatarios (preferentemente socios o bien terceros).

\begin{tabular}{|c|c|c|}
\hline \multirow[b]{2}{*}{$\begin{array}{l}\text { Tipo de servicios } \\
\text { producidos }\end{array}$} & \multicolumn{2}{|c|}{ D estinatarios de los servicios de las organizaciones } \\
\hline & $\begin{array}{l}\text { Preferentemente } \\
\text { el interior } \\
\text { (para socios) }\end{array}$ & $\begin{array}{l}\text { Preferentemente } \\
\text { el exterior } \\
\text { (para no socios) }\end{array}$ \\
\hline $\begin{array}{l}\text { De tipo particular } \\
\text { y específico }\end{array}$ & $\begin{array}{l}\text { 1. O rganizaciones de } \\
\text { auto/mutua ayuda y de } \\
\text { cooperación tradicional }\end{array}$ & $\begin{array}{l}\text { 2. O rganizaciones } \\
\text { cooperativas de } \\
\text { solidaridad social }\end{array}$ \\
\hline $\begin{array}{l}\text { De tipo universal } \\
\text { y difuso }\end{array}$ & $\begin{array}{l}\text { 3. o rganizaciones que } \\
\text { gestionan servicios de } \\
\text { privado social (por } \\
\text { ejemplo escuelas) para } \\
\text { los propios socios }\end{array}$ & $\begin{array}{l}\text { 4. O rganizaciones } \\
\text { que gestionan } \\
\text { servicios de utilidad } \\
\text { pública }\end{array}$ \\
\hline
\end{tabular}

Fuente: P. D onati, G. Rossi (1995).

Ti pologías basadas en la estructura organizativa. Según A. Ardigo, podemos distinguir las organizaciones de tercer sector a partir de varios criterios:

1. La forma jurídica: pueden ser organizaciones de hecho, cooperativas, organizaciones de voluntariado, formas de sociedad legalmente reconocidas.

2. El nivel territorial: pueden ser locales, regionales, nacionales y supranacionales.

3. El modelo organizativo: puede hacerse referencia al nivel de flexibilidad de los roles, al nivel de profesionalización (trabajadores dependientes/voluntarios), al tipo de gestión, al modelo de representación y de gobierno interno31.

Ti pologías basadas en el cambio organizativo. $\mathrm{N}$ inguna organización es fija. Su mission y estructura cambian en función de la edad, del crecimiento o reducción de las dimensiones, de las mutaciones del ambiente externo. Una de las más simples y útiles tipologías de las organizaciones nonprofit es la desarrollada por $\mathrm{H}$ andy ${ }^{32}$. En ella se combinan muchas de las variables anteriormente mencionadas (quien es el beneficiario; grado de accesibilidad; fines expresivos versus instrumentales, etc.) con una teoría del cambio.

$\mathrm{H}$ andy distingue tres tipos de organizaciones:

a) O rganizaciones de mutuo apoyo/ayuda. Son aquellas organizaciones creadas con el fin de poner a personas con un problema particular o con un parti- 
cular entusiasmo en contacto con otras que les pueden dar su comprensión, consejo, apoyo y empuje. Éste es el modo a partir del cual nacen muchas organizaciones de tercer sector.

b) O rganizaciones de servicio. Son organizaciones instrumentales que se otorgan el objetivo o la tarea de elaborar servicios a personas que tienen necesidad. G eneralmente suelen emplear personal pagado.

c) O rganizaci ones «campai gning». Son organizaciones creadas para propagar una causa o para obrar como un grupo de presión en favor de un particular tema o interés.

Según $\mathrm{H}$ andy, cada uno de estos tipos lleva consigo una teoría no expresa sobre la naturaleza de la organización y sobre como debería estar gestionada. Los grupos de ayuda mutua tienen necesidad sólo de la organización mínima indispensable para servir a los miembros, para hallar los motivos de los encuentros y para publicarse. Todos los interesados pueden acceder sin sufrir verificaciones o tests. La administración es considerada una pérdida de tiempo, o una distracción del verdadero fin, y se mantiene en el límite necesario al bien del grupo.

Las organizaciones de servicio, sin embargo, se esfuerzan por ser profesionales, eficientes y eficaces. D e ello se sigue que deben ser selectivas en el reclutamiento, exigentes en la revisión de los estándars, preparadas para retroceder si es necesario e, incluso, dispuestas a dejar a quien no está en situación de desempeñar el propio trabajo. Uno no puede escoger el unirse a la dirección de la organización. En efecto, tienden a ser burocráticas en el sentido de que las tareas son definidas formalmente, con responsabilidades formales y formales verificaciones de sus actuaciones: la organización debe ser capaz de continuar actuando del mismo modo también si cambian los individuos.

Las organizaciones de propaganda son guiadas más que gestionadas. También necesitan de una administración, pero ésta es subordinada y, preferiblemente, invisible. La esencia de la organización es la de adherise a una causa, de converger sobre un líder, a menudo carismático, cuya personalidad contagia a la organización. La única cualidad para la pertenencia es tu fe, y cuanto más crees, tanto mejor.

Cada conjunto de principios es internamente coherente y produce modos diversos de organizar. El problema nace en el momento en que la organización de ayuda mutua se transforma con el tiempo en una organización de servicio o cuando una organización comienza a hacer publicidad. En estos momentos de cambio, el encuentro entre diversos principios es inevitable.

Siguiendo el mismo planteamiento, Rowe sostiene un tránsito desde el selfhelp a las organizaciones de tipo altruista, desde las expresivas a las instrumentales, desde la ayuda mutua a la organización de servicio, el cual produce correspondientes cambios en la estructura organizativa. También subraya este autor importantes cuestiones sobre los efectos que este tránsito tiene sobre el carácter «participativo» de las organizaciones del tercer sector; sobre el desen- 
volvimiento de los miembros y de los usuarios en la decisiones más importantes; sobre su capacidad de ser efectivamente capaces de dar cuentas 33 .

\section{Factores y procesos de cambio}

M uchas de las investigaciones sobre el cambio en las organizaciones del tercer sector, más que interesarse en los tipos de organización, han prestado atención a cómo tiene lugar dicho cambio y a las consecuencias que produce sobre la organización. En líneas generales, se basan en teorías amplias de las organizaciones que se aplican, por tanto, a todos los sectores.

Powell y Friedkin han identificado tres grandes planteamientos del cambio organizativo que son aplicables a todas las organizaciones, independiente mente del sector 34 . El primer planteamiento lee el cambio como una reacción a las condiciones internas de la organización. Por ejemplo, en el sector del mercado, el tránsito de la organización funcional a la multifuncional es una respuesta al crecimiento de las dimensiones de la empresa. La ley de hierro de la oligarquía, de M ichels, se englobaría en esta categoría de las explicaciones del cambio: «para mantener sus posiciones de prestigio en las organizaciones, Ios participantes emplean más energía en las actividades que les sirven, que en aquellas orientadas a los fines de la organización».

Según Powell y Friedkin, las organizaciones del tercer sector son particularmente vulnerables a esta ley, no sólo a causa del crecimiento de la profesionalización, sino, también, porque los líderes fácilmente piensan que ellos solos entienden realmente la organización, estando englobados sólo parcial o escasamente los voluntarios y los socios. Aún más, para estos autores las organizaciones del tercer sector están caracterizadas por la confianza plena, en la cobertura de las cargas más importantes, en las figuras de los líderes carismáticos. Esta característica conlleva el hecho de que, para las organizaciones del tercer sector, el proceso de sustitución de los propios dirigientes sea extremadamente problemático y doloroso. Con frecuencia da lugar a crisis que se resuelven con fenómenos de rediseño complejo de la organización (refundación o renacimiento) ${ }^{35}$. En la misma línea se sitúan las aportaciones de M oss K anter y Summers. En su estudio sobre la difusión de los procesos de innovación, pusieron de manifiesto como las organizaciones del tercer sector estaban caracterizadas por una rigidez organizativa que hacía difícil innovar y cambiar. Entre los el ementos estructurales individuados que impedían el cambio, estos autores destacaron el rol jugado en la legitimación de la innovación por parte de los líderes y de los miembros más ancianos 36 .

El primer planteamiento de Powell y Friedkin ha sido matizado y completado por $\mathrm{J}$. Wolf. Para ésta última, todo proceso de cambio organizativo 
comprende dos dimensiones: a) técnico-estructural; b) las relaciones humanas. Ambas deben proceder de manera paralela y relacionada. Por otra parte, reconoce que todo cambio organizativo es un proceso y no un acontecimiento, lo que implica la adopción de una serie de pasos y etapas intermedias antes que la completa realización. La participación es, según Wolf, otro factor clave para determinar el éxito o no del proceso. Éste último resulta especialmente importante en las organizaciones del tercer sector, ya que son organizaciones centradas en el factor humano.

A partir de estas premisas, Wolf consigue individuar algunas características que, en su opinión, obstaculizan la adopción de innovaciones o cambios en las organizaciones del tercer sector:

- Su naturaleza nonprofit.

- La amplitud e indeterminación de sus finalidades.

- Las características de las necesidades puestas por el ambiente.

- El carácter mixto de los trabajadores: personal dependiente y voluntarios.

- La creciente estructura mixta (que comprende actividades de recogida de fondos, comerciales, elaboración y distribución de prestaciones y servicios) ${ }^{37}$.

El segundo planteamiento de Powell y Friedkin, reductivo en cuanto que sólo se orienta a los factores económicos, subraya la tendencia de las organizaciones a modificar sus estructuras y sus objetivos con el fin de obtener los recursos necesarios para sobrevivir. Este planteamiento de la dependencia de los recursos ${ }^{38}$ sugiere, por ejemplo, que las organizaciones del tercer sector adaptarán sus estructuras y sus fines a los del público a medida que vayan progresivamente dependiendo de éste para su financiación. En mi opinión, las empresas de mercado son más plásticas y flexibles, en cuanto que su fin último - ganar beneficios para sus accionistas- les permite una considerable libertad en la elección de los medios para alcanzar tal objetivo. En línea teórica, una empresa puede cambiar la gama de producto, rechazar algunos servicios, cambiar 0 vender algunas prestaciones, mientras que la mission de una organización del tercer sector, bien sea de tipo solidario, educativo o cultural, establece una mayor limitación en la flexibilidad de las acciones. Los motivos no son otros que las consecuencias derivadas del abandono de la mission, ello puede conllevar una serie de problemas legales y fiscales.

El tercer planteamiento es más comprensivo en cuanto que tiene presente los factores de tipo sociocultural. Explica el cambio como resultado del «isomorfismo institucional»39. En síntesis, este planteamiento hipotiza la existencia de «campos organizativos» constituidos por abastecedores principales, consumidores de recursos y de productos, agencias de regulación y otras organizaciones que producen productos y servicios similares. A partir del 
crecimiento de la interacción, del intercambio de informaciones, del desarrollo de estructuras de prestigio y de un modo de pensar institucionalizado, es decir, de la tendencial transformación «de los campos» en «redes organizativas», las organizaciones que operan en el mismo campo alteran sus estructuras y comportamientos para configurarse a las normas del campo o de la red.

Por ejemplo, algunos sostienen que las organizaciones del tercer sector están pareciéndose siempre más a los departamentos locales de los servicios sociales a medida que interactúan con ellos en el proceso de contracting-out 40 o de conciertos, asumiendo de las autoridades locales fines y valores, estructuras y procesos que facilitan las estipulaciones del concierto. O bservaciones análogas han sido hechas sobre los efectos de las donaciones por parte de las empresas: las organizaciones receptoras tienden a adoptar el comportamiento, las estructuras y los procesos que las empresas donantes consideran aceptables y en los que tienen confianza. Sobre este tema, especialmente interesantes resultan las aportaciones de Bauer. Para el sociólogo alemán, este aspecto constituye uno de los principales puntos de debilidad de las organizaciones del tercer sector. D efinidas como instrumentos canales de intermediación - sin la existencia de una configuración estructural e institucional como la que poseen las agencias estatales o las empresas de mercado- , la proximidad e interacción con las agencias estatales conlleva el inicio de un proceso de burocratización y centralización que las hace convertirse en un apéndice del Estado, con una fuerte connotación autoritaria. Por otra parte, la proximidad e interacción con las empresas de mercado, siempre según Bauer, deriva en la prevalencia de la dimensión empre sarial, olvidándose de todo objetivo prosocial41.

\section{C aracterísticas específicas de las organizaciones del tercer sector}

En los apartados precedentes he tratado de ilustrar la variedad y la complejidad del tercer sector. También he intentado presentar, sumariamente, algunas de las formas en que se ha intentado articular esta variedad, distinguiendo por tipos de organizaciones dentro del tercer sector. C reo que los elementos ofrecidos son suficientes para entender que la creación de organizaciones del tercer sector es un proceso generalizable que se especifica a partir de las relaciones internas y externas (entre la organización y su ambiente) a la organización, y que tales relaciones se refieren no sólo a los factores económicos, sino también a las «normas» que progresivamente se desarrollan en los «diversos campos organizativos».

M ás explícitamente, para el estudio de las formas organizativas del tercer sector es oportuno proceder val orando los parámetros de las relaciones internas y de las relaciones con el exterior. D onde sea posible, se trata de analizar las interrelaciones entre relaciones internas y relaciones externas, ya que la organización es un problema de diseño, mantenimiento y variación de los límites 
entre interno y externo. En mi opinión, los parámetros que resultan más útiles y significativos para el análisis de las formas organizativas son:

a) Internos. la estructura de las tareas y de las cargas, los tipos y grados de recompensas por roles realizados en el interior y en el exterior, la movilización de los recursos del ambiente interno, los procesos de decisión (previstos y de hecho realizados), las modalidades electivas de las cargas y de formación de la policy colectiva, las modalidades de rendir cuentas los propios miembros. Todos estos parámetros pueden ser valorados a la luz de diversos criterios: el grado de participación permitido por las modalidades de decisión (si decide pragmáticamente el singular operador, si deciden todos conjuntamente, si deciden los órganos directivos o el presidente, etc.), el grado de flexibilidad en la división del trabajo social y político, etc.

b) Externos. las modalidades de acceso y de salida de los miembros, las modalidades de financiación y de obtención de los recursos del exterior, las facilidades externas para la realización de los roles internos, las formas de reconocimiento requeridas desde el punto de vista jurídico en las relaciones con el Estado y en la contratación con otras agencias públicas y privadas, los modos de rendir cuentas de las propias acciones y de los resultados obtenidos a las instituciones y entes externos. I gual que los parámetros internos, éstos pueden ser valorados a la luz de diversos criterios: la mayor o menor selectividad de los requisitos solicitados para convertirse en miembro, la mayor o menor dependencia de ciertas instituciones (por línea general aquéllas que constituyen las mayores fuentes de financiación), etc.

D e todo lo anterior emerge la siguiente afirmación: no existe una organización «típica» del tercer sector, así como no existe una organización «típica» del mercad 02. Ahora bien, con la cautela necesaria, ¿es posible individuar cuáles son las distinciones directrices, es decir, los elementos que permiten distinguir las organizaciones del tercer sector de las que operan en el mercado y de las organizaciones públicas?

Los intentos para individuar los criterios definidores de las organizaciones del tercer sector son actualmente muy numerosos y no es cuestión de retomarlos analíticamente. En síntesis, se puede decir que ninguno de ello resulta plenamente satisfactorio en cuanto que culminan por presentar al tercer sector como «sector mixto», es decir, como una combinación o mediación entre los

42. Buena parte de las organizaciones del tercer sector surgen como iniciativas informal es que, con posterioridad, se van formalizando y, paral elamente, van asumiendo modalidades ope rativas diversamente articuladas que erigen, de cualquier manera, como jefe al «grupo primario» o fundador. Si tal grupo consigue o no mantener su unidad, o bien decide escindirse y dar vida a unidades separadas, así como grupos independientes puedan y deban agregarse de cual quier manera, todo ello depende de una serie de variables como: los recursos, las capacidades de gestión, los model os y las dinámicas relacional es adoptadas. D ichas variables pueden ser obstaculizadas, o bien favorecidas, por la legislación de un sistema políticoadministrativo y por las relaciones con el mercado. 
elementos característicos del polo público y los típicos del polo privado. C reo que es más apropiada la interpretación presentada por P. D onati. Para el sociólogo italiano, el tercer sector debe ser leído como:

- un modo de ser positivo y propositivo de la sociedad (antes que como un tipo de relaciones social es que se difunden por reacción negativa o por salida respecto a otras relaciones o instituciones);

- una forma social emergente que nace de la exigencia de diversificar las respuestas a específicas necesidades sociales que siguen dinámicas de descomposición y multiplicación y que siempre solicitan nuevos relacionamientos.

En breve, el tercer sector y sus organizaciones deben ser comprendidos y explicados como producto de la diferenciación societaria en condiciones de creciente complejidad social43.

Sin la pretensión de decir la última palabra sobre un tema bastante difícil, intentaré proponer algunos elementos que, espero, puedan ser útiles para interpretar el fenómeno.

I. Ausencia de fines de lucro, no redistribución de beneficios, finalidades sociales. Viene considerada por muchos como la característica más distintiva de las organizaciones del tercer sector. Propiamente, la ausencia del fin de lucro no significa que estas organizaciones no puedan tener beneficios mediante particulares áreas de actividad, sino que el beneficio no es el objetivo que justifica la creación y supervivencia de la organización. C uando exista, no es distribuible, bajo ningún concepto, entre los asociados en forma de útil. Este principio, considerado hasta ahora como inderogable, ha encontrado una limitación en la legislación belga que, recientemente, ha introducido en el derecho mercantil la figura de la «sociedad con finalidad social». Estas sociedades se caracterizan «por no ser constituidas para el enriquecimiento de sus asociados» (apartado I, art. 164 bis) y por el hecho de que en sus estatutos establecen «que los asociados no buscan al gún beneficio patrimonial o un beneficio patrimonial limitado» (apartado II).

Por tanto, como se ve, también el principio de la no distribución de los beneficios es relativo y no absoluto, por lo que su poder de discriminación tiende a reducirse en favor de la finalidad «social» de la iniciativa. Este término, que la ley belga no especifica, es entendido como distinción-guía no sólo respecto al mercado, caracterizado por la finalidad del beneficio, sino también respecto a la comunidad o grupo primario, en el sentido de que la organización se constituye para realizar acciones y tareas que van más allá de los límites de las solidaridades primarias44. El nacimiento de las organizaciones del tercer sector, en consecuencia, representa el modo a 
través del cual los grupos sociales deciden, de manera autónoma, el producir directamente bienes y servicios colectivos, de tipo material o inmaterial, cuya disponibilidad tendrá, a través del complejo juego de la interdependencia, uno o más efectos positivos sobre la calidad de vida de la sociedad. Estos efectos positivos no podrán retroobrar sobre el grupo en la forma del incrementeo de útil económico de sus miembros, sino en una medida limitada ex ante por la legislación estatal.

II. La presencia de voluntarios. También a causa del vínculo sobre la posibilidad de procurar a los asociados un beneficio patrimonial directo o indirecto, las organizaciones del tercer sector se distinguen por estar basadas, de manera significativa, en la participación de voluntarios. Su presencia es una distinción muy clara respecto a las organizaciones de mercado, ya que en éstas últimas, la misma legislación no prevé la posibilidad de colaboraciones gratuitas. Parece menos discriminante respecto a las organizaciones públicas, en cuanto que en éstas es posible desempeñar o realizar trabajo voluntario.

Sin embargo, se considera que, en las organizaciones públicas, el voluntariado se configura como un rol accesorio y opcional, en el sentido de que no pueden cubrir tareas institucionalmente asignadas a la organización y que su presencia no puede jamás ser considerada indispensable o necesaria. En las organizaciones del tercer sector es necesario y central, en el sentido de que también las organizaciones de servicio más estructuradas, enteramente basadas sobre staff operativos de profesionales pagados, deben valerse de voluntarios al menos para los órganos directivos, es decir, para aquellos roles que, en última instancia, definen la estrategia de la organización.

D esde el momento en que constituye un elemento discriminante, es muy interesante preguntarse por qué los voluntarios se convierten en tales, esto es, por qué las personas se ponen a crear y/o trabajar para organizaciones que no les pagan y por las que no quieren ser pagadas.

También en este caso podemos hacer referencia a la distinción de G ordon y Babchuk, y responder que existen tanto motivaciones de carácter expresivo (esto es, para expresar y satiffacer los intereses de los propios miembros), como motivaciones de carácter instrumental (es decir, hacer cosas para que los otros y/o con los otros). En este contexto, con el primer término, intento hacer referencia al hecho de que en nuestro país, como en otras zonas del mundo, está en curso un proceso de cambio cultural también en relación con la esfera de los derechos sociales de la ciudadanía. Las personas y los grupos que crean y/o participan en las organizaciones del tercer sector expresan una cultura de la ciudadanía «de las autonomías sociales»45 que va más allá de la concepción welfarista o lib-lab de la ciudadanía, y que por ello no se reconoce, y no es comprensible, dentro de la dicotomía público-privado o Estado-mercado. 
U sando el lenguaje del planteamiento transaccional para aclarar los aspectos instrumentales, podemos decir que en un contexto en el que las recompensas de tipo monetario no son suficientes para dar sentido al trabajo, los voluntarios están a la búsqueda de recompensas de tipo psicológico y/o relacional, como aquéllas que provienen del hacer cualquier cosa buena, útil, importante para la sociedad, de participar y pertenecer a un movimiento social que trabaja para cambiar a mejor la sociedad46.

Lo que muchos voluntarios parecen solicitar a las organizaciones del tercer sector a cambio de su prestación gratuita es, en esta perspectiva, aquello que Parsons definía como personal achivement, es decir, aquel sentido de realización personal que las sociedades industrializadas avanzadas de los años cincuenta y sesenta vinculaban a la ganancia monetaria y al rol laboral. Esto tiene, evidentemente, consecuencias para el management de las organizaciones de Tercer Sector. En efecto, para sostener la presencia de voluntarios, muchos de los cuales pueden estar enrolados por los motivos dichos anteriormente, las organización debe crear un ambiente de trabajo «amigable», fundado en un ethos sociable y de sociabilidad, y mutante, es decir, capaz de renovar continuamente los motivos ideales que ligan al individuo a la organización. El riesgo intrínseco a esta necesidad organizativa es que se pierda una coherente orientación al servicio y que las tareas vengan definidas y asignadas a partir de las características de los voluntarios y no viceversa.

Este éxito, ciertamente negativo si se valora con el parámetro de la eficiencia productiva y de la performance haciendal, puede también derivar de dos condiciones posteriores que parecen caracterizar a este tipo de organizaciones. La primera es una condición tendencial mente igualitaria de la participación que lleva a los voluntarios a tener sentido limitado de las jerarquías. La segunda es una exigencia de tendencial coherencia entre interno y externo, o entre objetivos y modelos organizativos. En otros términos, una organización que, por ejemplo, tiene como objetivo el integrar socialmente a las personas mental mente débiles, ¿puede no tener el mismo planteamiento en la relación con sus voluntarios?

Como se ve, la presencia de voluntarios crea específicos problemas a la gestión de estas organizaciones. Por otra parte, a pesar de las dificultades mencionadas, el hecho de que las organizaciones del tercer sector consigan, en buena medida, realizar sus objetivos y, sobre todo, mantener y conservar en el tiempo cantidades importantes de trabajo voluntario, ha lle vado a los más atentos estudiosos de management a sugerir procesos de aprendizaje recíproco entre organizaciones profit y nonprofit, para mejorar, en el primer caso, las motivaciones y el sentido de pertenencia de los trabajadores pagados, en el segundo caso, la performance y la eficacia organizativa47. 
III.EI ethos igualitario y participativo. Como he señalado anteriormente, las organizaciones del tercer sector tienen carácter «social», es decir, nacen desde grupos sociales (asociaciones) o por finalidades sociales, y se avalan necesariamente de la participación de voluntarios. Ambas características producen la tercera, esto es, un específico ethos organizativo que da valor a la igualdad y a la participación.

Billis contrapone las asociaciones que son afectivas, expresivas y democráticas, a las burocracias organizativas, sean públicas o privadas de beneficio, en cuanto que son instrumentales, jerárquicas y no democráticas. Según el estudioso inglés, las organizaciones del tercer sector se ubican en la línea que enlaza estos dos extremos, en una posición que dependerá prácticamente del compromiso realizado entre las reglas del juego asociativo y las del mundo burocrático. La presencia de este ethos no depende sólo del hecho de que la gran mayoría de las organizaciones del tercer sector constituye el desarrollo de un momento inicial de tipo asociativo, sino también de las específicas características que tienen estas organizaciones de manera diversa.

La primera es la finalidad social, es decir, el hecho de tener como objetivo el hacer participar en la vida social a personas excluidas y marginadas y/o dar voz a necesidades y problemas no adecuadamente considerados. A este objetivo externo debe corresponder, de cualquier manera, un modelo organizativo participativo y lo más posible igualitario.

La segunda característica consiste en la presencia preponderante de voluntarios y de operadores profesionales 48 . Por diversas razones, sea los voluntarios o los profesionales, pueden esperarse o pedir el derecho a controlar no sólo el propio trabajo, sino también los valores, los objetivos y los proyectos de la organización.

IV. Separación entre consumidores finales y financiadores. Es una característica que hace referencia a las organizaciones que elaboran servicios a terceros no miembros de la organización, por tanto, en concreto, los grupos de voluntariado, las cooperativas sociales y las fundaciones. D iversamente a cuanto sucede en el sector del mercado, para las organizaciones non profit la elaboración de servicios (output) está normal mente separada de la adquisición de recursos (input), también en el caso de que por principio la organización prevea el pago de las prestaciones por parte de quien tiene un cierto nivel de ingresos. Esto significa, entre otras cosas, que la organización debe servir a los propios clientes usuarios para conseguir la propia finalidad, pero que para sobrevivir debe «agradar» a quien ofrece la financiación. D e esta separación se derivan al gunos riesgos que son específicamente atribuibles a estas organizaciones. 
El primero consiste en la posibilidad de que el producto/servicio venga incorporado a una imagen del mismo mucho más rica que la propia realidad 49 .

El segundo es que la organización se dedique a producir bienes o servicios que son de hecho marginales o irrel evantes para sus clientes usuarios, pero que los financiadores donantes, o por ignorancia o a causa de los diversos valores de referencia, están felices por financiar.

D rucker ha avanzado un problema diverso, el cual considera típico de las organizaciones que define como «instituciones de servicio público» y que están caracterizadas por la separación entre financiadores y consumidores ${ }^{50}$. Estas organizaciones son pagadas a base de sus esfuerzos, no sobre la base de sus resultados, gracias a los fondos que cualquier otro ha puesto a su disposición. Cuanto mayor es el esfuerzo en el que una organización de servicio público se compromete, mayor será su budget, y la dimensión de su budget más que sus resultados es el modo en que ella define el éxito. D e ello se sigue que toda reducción de actividad será leída como una reducción del éxito de este tipo de instituciones. Por lo que existe, concretamente, la posibilidad de que no vengan nunca reconocidos los errores y que se continúe a llevar hacia delante proyectos que han demostrado ser ineficaces.

Sin embargo, va subrayado que esta crítica de D rucker no se aplica sólo a las organizaciones del tercer sector, sino, en general, a todas las organizaciones, públicas y privadas, que elaboran servicios no financiados por los usuarios.

\section{Conclusiones}

Las organizaciones del tercer sector son organizaciones creadas para finalidades sociales; que se avalan, de una manera determinante, de la participación de voluntarios que se basan en un ethos que valora la igual dad y la participación, por tanto, modelos de gestión más democráticos que aquéllos típicos de las organizaciones burocráticas, y cuyos recursos no provienen de los consumidores finales.

Pueden ser creadas para elaborar cualquier tipo de bien o servicio, material o inmaterial, que responda a necesidades colectivas más amplias que aquellas de los singulares grupos primarios. Se multiplican porque el cambio o mutamiento sociocultual que interesa a Europa ha caminado, en buena medida, en la dirección de la elaboración de una «ciudadanía de las autonomías sociales», aunque ha faltado el pleno reconocimiento institucional de la misma. Por tanto, se puede hipotizar que, en el caso de que tal reconocimiento institucional venga plenamente realizado, asistiremos a un posterior crecimiento de estas organizaciones. 
La legitimación sólo parcial de las organizaciones del tercer sector también ha impedido que se creasen entre éstas, las organizaciones públicas y las de mercado, dentro de los sectores productivos, «campos organizativos» verdaderos y propios, en el interior de los que se habrían podido realizar aquellos procesos de adecuación relacional o de aprendizaje recíproco que $\mathrm{Di}$ M aggio y Powell han definido como «isomorfismo organizativo».

En este sentido se puede sostener que, a pesar del crecimiento numérico y el aumento de su peso porcentual en la gestión de los servicios financiados públicamente, las organizaciones del tercer sector en Europa continúan viviendo en una situación de marginalidad51. También bajo el perfil del estudio de los modelos de gestión y operativos utilizados que, sin embargo, en los países en los que el tercer sector ha tenido desde hace tiempo plena ciudadanía institucional, se ha convertido en un punto de referencia para procesos de aprendizaje organizativo que interesan, en concreto, a las organizaciones de mercado, pero también a las públicas 52 . D esde este punto de vista, retengo que la salida de la marginalidad del tercer sector contribuirá a ofrecer al debate sobre la innovación organizativa puntos de reflexión particularmente significativos y útiles.

\section{Bibliografía}

Alary, J. (ed.). (1988). Solidatités. Pratiques de rechercheaction et de prise en charge par le milieu. M ontreal: Boreal.

An HeIER, H .K.; Rudney, G.; SAlom ON, L.M . (1992). «T he N onprofit Sector in the U nited N ations System of $\mathrm{N}$ ational Accounts: D efinition, Treatment, and Practiques. Working Papers of the Johns H opkins ComparativeN on profit Sector Projet, 4. Baltimore: The Johns H opkins Insitute for Policy Studies.

ANTH ONY, R.N .; YOUNG, D.W. (1990). Characteristics of N on profit Organizations. Berlín, N ueva York: D eG uyter Publications.

ARCHER, M . (1995). Realist Social Theory: The M orphogenetic Approach. Cambridge: Cambridge University Press.

ARd IGO , A. (1981). «Voluntariato, Welfare State e Terza D imensione». La Richerca Sociale, 25, p. 7-22.

- (1992). «C onoscere il voluntariato: bilanci e prospettive della ricerca sociologica». La Ricerca Sociale, 42.

BARBETTA, G .P. (1994). «Le dimensioni economiche del settore non profit en Italia». Q uaderni occasionali, 5. M ilán: IRS.

- (1994). «Sul contracting out nei servizi sociali e sanitari». Impresa Sociale, 15, p. 18-31.

BART LETT, W. (1994). «La contrattazione nei servizi sociali in Gran Bretagna». Impresa Sociale, 14, p. 27-36.

BASSANINI, M.C.; RANCI, P. (eds.). (1990). «N on per profitto. II settore dei soggetti che erogano servizi di interesse collettivo senza fine di lucro». M ilán: Fondazione A. Olivetti. 
BAUER, R. (1993). «Voluntary Welfare Associations in Germany and the U nited States: Thess on the H istorical D evelopment of Intermediary Systems». Voluntas, vol. I, núm 1, p. 97-116.

BERGER, J. (1992). The Future of Capitalism. Berkeley: U niversity of California Press. Bern Stein, S.R. (1991). M anaging Contracted Services in the N on profit Agency. Philadel phia: Yale U niversity Press.

BILLIS, D. (1990). «Planned Change in Voluntary and Government Social Service Agencies». En Towards the 21 th Century Challenges for the Voluntary Sector, Proceedings of the 1990 of the Association of Voluntary Sector Scholars. Londres: CVO.

BITTKER, B.I .; RAHDERT (1976). Researching the Voluntary Sector. Tonbridge: Charities Aid Foundation.

BLAU, P.M .; SCH OTT, R.W. (1962). Formal Organizations: a Comparative Approach.

San Francisco: Chandler.

BoCCACIN, L. (1993). La sinergia della differenza. M ilán: Angeli.

CatTARIn U SSI, B. (1994). Altruismo e soci etá. M ilán: Angeli.

Cesareo, V. (1978). «C ittadinanza e Stato asistenziale». Studi di Sociologia, XVII, núm. 3, p. 152-193.

CHARMET, G. (1985). « nformal support networks among the elderly». Research on Aging, vol. 5, núm. 1, marzo, p. 1-18.

ChILlEMI, O . (1989). «I movimento cooperativo nella legislazione statale regionale». Animazione Sociale, n. 5, p. 77-88.

CLARK, P.B.; W ILSO N, J.Q . (1961). «ncentive Systems: A Theory of O rganizations». Administrative Science Q uaterly, 6, p. 129-166.

ColozzI, I.; BASSI, A. (1995). U na solidarietà efficiente. II Terzo Settore e le organizzazioni di voluntariato. Roma: La N ova Italia Scientifica.

Di M AGgIO, P.; POWELL, W.W. (1983). «T he Iron C age Revisited: Institutional I somorphism and Collective Rationality in O rganizational Frields». American Sociological Review, 48, p. 147-160.

D on ATI, P. (1978). Publico e privato. Fine de una alternativa? Bolonia: Capelli.

- (1991). Teoria relazionale della soci età. M ilán: Angeli.

- (1993). La cittadinanza societaria. Roma, Bari: Laterza.

- (1996). Sociologia del terzo settore. Roma: NIS.

D on ATI, P.; Co LozzI, I. (1994). La cultura della cittadinanza oltre lo Stato assistenziale. Roma: Edizioni Lavoro.

D o N ATI, P.; RosSI, G. (1995). Le associazioni familiari in Italia. M ilán: Angeli.

D RUCKER, P. (1985). Innovation and Entrepreurship. Londres: H einemann.

- (1989). «W hat Business C an Learn from N on-Profits». H avard Business Review, julio-agosto, p. 89-93.

- (1992). M anaging the N onprofit O rganization. Principles and Practices N ueva York: $\mathrm{H}$ aperBusiness.

Easley, D.; O 'H ARA, M . (1983). «O ptimal N on Profit Firms». En Rose-Ackerm an, S. (ed.). The E conomics of $\mathrm{N}$ on Profit Insitution. N ueva York: $\mathrm{O}$ xford U niversity Press, p. 85-93.

Etzioni, A. (1988). The M oral D imension: Towards a N ew Economics. N ueva York: Free Press.

GORD ON , C.W.; BABCHUK, N. (1959). «A Typology of Voluntary O rganizations». American Sociological Review, 24, p. 22-29. 
GRONBJERG, K .A. (1990). «M anaging N onprofit Funding Relations: C ase Studies of Six H uman Services O rganizations». Working paper, 156. PO N PO .

GuI, B. (1990). II ruolo delle organizzazioni mutualistiche esenza scopo di lucro. Bolonia: II Mulino.

H AN DY, C. (1988). Understanding Voluntary O rganizations. H armondsworth: Penguin Books.

H AN SM AN N , H .B. (1987). Economic T heories of N onprofit Organizations. En PowELL, W. (ed.).

- (1990). «T he R ole of N onprofit Enterprise». Pompo Working Paper, núm. 1; Yale Law University, núm. 89, abril, p. 838-898.

H ORSCH, H .D . (1993). «Resource Composition and O ligarchization». Comunicación presentada en la Conferencia sobre el Tercer Sector, Barcelona.

Jeavon S, T.J. (1993). The role of Values: M anagement in Religious O rganizations. San Francisco: $\mathrm{H}$ ollister.

Ken DALL, J.; KNAPP, M. (1993). «D efining the N onprofit Sector: The United Kindgom». Working Papers ot the J ohns H opkins Comparative N on profit Sector Project, 5. Baltimore: The Johns H opkins Institute for Policy Studies.

KenN NDY, L.W. (1991). «Q uatily M anagement in the N onprofit Worl». San Francisco: Jossey-Bass Publishers.

Kramer, R.M . (1987). «Professione». En De MachI; F. Ellen A, A. (eds.). Nuovo dizionario di sociologia. Paoline, Cinesello Balsamo.

LAZZARIN I, G . (1991). «Scambio politico eincertezza». Rassegna italiana di Sociologia, a. XXVI, núm. 1, p. 53-78.

LEAT, D . (1994). Similarities and D ifferences between For-Profit and Voluntary N onProfit O rganizations. Londres: Volprof.

LEPRI, S. (1993). «Le organizzazioni di voluntariato possono gestire e vendere servizi sociali?». Impresa Sociale, 10.

LU H M AN N, N . (1983). Teoria politica nello Stato del benessere. M ilán: Angeli.

- (1990). Sistemi sociali. Bolonia: II M ulino.

M CCAuley, C.D.; H ughes, M.W. (1993). «Leadership in H uman Services: Key Challenges and Competencies». En ANTH ONY, R.N.; Young, D.W. (ed.).

M ELIEF, W. (1992). «D utch Voluntary 0 rganizations in Transition». Comunicación presentada en The Third International C onference on Research of Voluntary and N on Profit O rganizations, Indianapolis.

M ELUCCI, A. (1984). Atri codici. Areedi movimento nella metropoli. Bolonia: II M ulino. M ID DLETON, M . (1987). «N onprofit Board of D irectors: Beyond the G overnance funtion». En POWELL (ed.).

M oss Kanter, R.; Sum mers, D.V. (1987). «Doing Well While Doing Good:

Dilemmas of Performance $M$ easurements in N on profit $O$ rganizations and The N eed for a M ultiple-Constituency Approach». En Pow ELL (ed.).

M ULLIN, R. (1980). Voluntary O rganizations and Social Welfare. Edimburgh: Oliver and Boyd.

N UtT, P.C.; BACKoff, R.W. (1992). Stategic M anagement of Public and Third Sector O rganizations. San Francisco: Jossey-Bass Publishers.

O LECK, H .L (1980). Social Enterprise. Londres: N ational C ouncil of Social Service.

O 'M ALLeY, P. (1983). O fferata privata di beni pubblici. Bolonia: II M ulino.

PACI, M . (1982). «O nde lunghe nello sviluppo dei sistemi di welfare state». Stato e M ercato, 6, p. 345-440. 
PERRI 6; VIDAL, I. (1994). D elivering Welfare Repositioning N on Profit and Co-O perative Action in Western European Welfare States. Barcelona: CIES.

Pfeffer, J.; Salan Cik, G.R. (1978). The External Control of O rganizations. Nueva York: H aper \& Row.

Phelan, M.L. (1987). Altruism, M orality and Economic Theory. N ueva York: Russel Sage.

PoweLL, W. (ed.). (1987). The N onprofit Sector: A Research H andbook. N ew H aven: Yale U niversity Press.

Powell, W.; FRIEDKIN, R. (1987). "O rganizational Change in Non-Profit O rganizations». En Pow ELL, W. (ed.).

RistuCCIA, S. (1995). Fondazioni eorganizzazioni del'azione volontaria. Roma: M aggioliQ ueste Istituzioni Ricerche.

Rose, A. (1967). The Power Structure: Political Process in American Soci ety. N ueva York: Oxford University Press.

RowE, A. (1978). «Participation and the Voluntary Sector: The Scope and Theory of Government-N onprofit Relations». Journal of Social Policy, 7.

SEIBEL, W. (1989). The Function of M ellow Weakness N onprofit Organizations as Problem N onsolvers in Germany. G lencoe: Free Press.

- (1990). Organizational Behavi our and O rganizational Function: Toward and M icromacro Theory of Third Sector. N ueva York: The Foundation C enter.

SILLS, D .L. (1957). The Volunteers. Glencoe: Free Press (IL.)

Stan TON, E. (1970). Clients C ome Last: Volunteers and Welfare O rganizations. N ueva York: Sage Publ.

Volunter CENTRE UK (1991). The 1991 National Survey of Voluntary Activity, Berkhamsted.

W AGNER, A. (1990). «O n Sharing: A Preface to Economic theory of Voluntary Action». N on profit and Voluntary Sector Q uaterley, vol. 20, núm. 4, p. 359-370.

WEISBRO D, B. (1988). The N onprofit E conomy. Cambridge: H arvard Univesity Press. W OLF, J. (1990). M anaging Change in N on profit O rganizations. N ueva York: The Foundations $C$ enter.

Yound, D .R. (1985). «W hat Business C an Learn from N onprofits». M odel s of Health and Human Services in the N onprofit Sector. Association of Voluntary Action Scholars. 